\title{
ASOSIASI TALI KUPU-KUPU (Bauhinia acuminata Blume.) DENGAN POHON INANG PADA PLOT MONITORING TAMAN WISATA ALAM GUNUNG MEJA MANOKWARI
}

\author{
(The Association Between Bauhinia acuminata Blume. With Hosted Plant in \\ Established Monitoring Plot of Gunung Meja Nature Tourist Park of Manokwari)

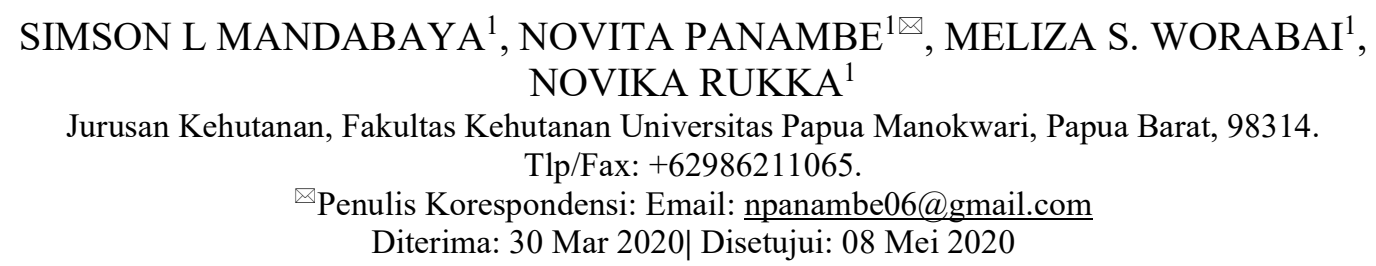

\begin{abstract}
Abstrak. Taman Wisata Alam (TWA) Gunung Meja merupakan salah satu ekosistem hutan tropis dataran rendah di Manokwari yang memiliki potensi flora dan fauna yang cukup beragam. Potensi flora yang ada di dalamnya memiliki hubungan atau persekutuan populasi-populasi yang kompleks, salah satunya adalah asosiasi antara tali kupu-kupu (Bauhinia acuminata Blume.) dengan pohon inangnya. Penelitian ini bertujuan untuk mengetahui asosiasi $B$. acuminata dengan pohon inang serta habitatnya pada hutan dataran rendah TWA Gunung Meja. Metode yang digunakan adalah metode deskriptif dengan teknik survei. Hasil penelitian menunjukan bahwa jumlah jenis pohon yang berasosiasi dengan B. acuminate adalah 10 jenis yaitu Pometia coreacea, Pometia pinnata, Alstonia scholaris, Artocarpus incissus, Pimelodendron amboinicum, Pterocymbium beccarii, Antiaris toxicaria, Streblus elongate, Medusanthera laxiflora dan Pterygota horsfieldii dengan jumlah individu terbanyak adalah Pometia pinnata sebanyak 11 pohon. Tingkat asosiasi $B$. acuminata dengan pohon inang $P$. pinnata adalah sangat erat $(2,506 \%)$, tingkat asosiasi $B$. acuminata kurang erat dengan pohon inang $A$. scholaris $(0,911 \%)$, P. amboinicum $(0,911 \%)$, dan tingkat asosiasi $B$. acuminata tidak erat dengan pohon inang P. coreacea $(0,683 \%)$, P. beccarii $(0,228 \%)$, A. toxicaria $(0,228 \%)$, A. incisus $(0,683 \%), P$. horsfieldii $(0,683 \%)$, S. elongata $(0,456 \%)$ dan M. laxiflora $(0,456 \%)$.
\end{abstract}

Kata kunci: asosiasi, tali kupu-kupu (Bauhinia acuminata Blume.), taman wisata alam, gunung meja, manokwari

\begin{abstract}
Gunung Meja Nature tourist Park is one of the low land tropical forest ecosystems in Manokwari which had various potention of its flora and fauna. The flora potention had relation or complex population, one of them is association between tali kupu-kupu (Bauhinia acuminata Blume.) with its host tree. The purpose of the study was to describe the asociation of B. acuminata with its host tree and its habitat at the low land at Gunung Meja Nature Tourist Park. The method used description with survey technique. The resluts showed that the total population of the trees associating with $B$. acuminate. There were 10 species i.e. Pometia coreacea, Pometia pinnata, Alstonia scholaris, Artocarpus incissus, Pimelodendron amboinicum, Pterocymbium beccarii, Antiaris toxicaria, Streblus elongate, Medusanthera laxiflora, and Pterygota horsfieldii which dominated by Pometia pinnata 11 trees. The association relation level of $B$. acuminata with the host tree P. pinnata was very close $(2.506 \%)$ while association relation level of $B$. acuminata was quite close with the host tree of $A$. scholaris $(0.911 \%)$, P. amboinicum $(0.911 \%)$, and the association level B. acuminata was not close


with the host tree P. coreacea (0.683\%), P. beccarii $(0.228 \%)$, A. toxicaria $(0.228 \%)$, A. incisus (0.683\%), P. horsfieldii (0.683\%), S. elongata (0.456\%), and M. laxiflora (0.456\%).

Keywords: association, tali kupu-kupu (Bauhinia acuminata Blume.), natural tourism park, gunung meja, manokwari

\section{PENDAHULUAN}

Papua merupakan salah satu pulau terbesar di Indonesia dengan luas hutan \pm 41 juta ha, memiliki kekayaan berupa keanekaragaman biodiversitas flora dan fauna yang sangat tinggi jika dibandingkan dengan daerah-daerah lain di Indonesia (Lekitoo et al. 2017). Johns (1997), menyebutkan bahwa jumlah flora di Papua diperkirakan sekitar 20.000-25.000 jenis. Keanekaragaman hayati yang tinggi ini dikhawatirkan akan mengalami tekanan yang disebabkan karena laju pembukaan hutan karena adanya otonomi khusus, pemekaran beberapa wilayah dan praktek illegal logging.

Kabupaten Manokwari sebagai salah satu daerah di provinsi Papua Barat memiliki kawasan hutan seluas 1.415.982 ha serta memiliki kekayaan biodiversitas flora dan fauna yang cukup tinggi (Wattimury 2007). Potensi tersebut telah mengalami tekanan sebagai akibat dari konsekuensi pemekaran wilayah dan otonomi khusus. Salah satu langkah awal untuk mencegah kerusakan hutan dan kepunahan spesies adalah dengan melakukan penelitian konservasi jenis (ex-situ dan in-situ).

Liana merupakan salah satu kelompok jenis tumbuhan yang banyak dijumpai pada hutan alam tropis di Kabupaten Manokwari. Liana merupakan salah satu tumbuhan berkayu merayap, memanjat dan membelit yang banyak dijumpai pada hutan tropis secara umum. Hal ini sejalan dengan pendapat Ewusie (1990), yang menyatakan bahwa meskipun kawasan hutan tropis kaya akan keanekaragaman jenis flora namun terdapat keseragaman spesies tampak sangat nyata dimana liana, anggrek dan tumbuhan pencekik merupakan ciri utama dari hutan tropis tersebut. Beberapa jenis liana sering dimanfaatkan oleh masyarakat disekitar kawasan sebagai tali pengikat dalam pembuatan rumah, pagar, kayu bakar serta pemanfaatan air yang terdapat pada tali tersebut sebagai air minum.

Taman Wisata Alam (TWA) Gunung Meja merupakan salah satu ekosistem hutan tropis dataran rendah di Kabupaten Manokwari yang memiliki potensi flora dan fauna yang cukup beragam. Letaknya yang sangat dekat dengan kota Manokwari dan adanya pemanfaatan hutan dan hasil hutan (kayu dan bukan kayu) yang cukup tinggi oleh masyarakat di sekitar kawasan tersebut dikhawatirkan akan menimbulkan penurunan spesies flora dan fauna yang terdapat di dalam kawasan tersebut. Potensi flora yang ada di dalamnya memiliki hubungan atau persekutuan atau gabungan populasi-populasi yang kompleks salah satunya adalah asosiasi antara liana Bauhinia acuminata Blume dengan inangnya. Asosiasi liana $B$. acuminata bersifat epifit (tidak merugikan inangnya). Liana ini biasanya tumbuh dan berasosiasi dengan jenis komersil atau jenis pohon lainnya, sehingga perlu diketahui bagaimana aspek ekologinya baik habitat liana $B$. acuminata maupun asosiasi yang terjadi antara liana tersebut dengan inangnya.

Berdasarkan fakta tersebut, maka perlu dilakukan penelitian guna mengetahui aspek ekologis yang sangat penting yaitu asosiasi 
dimana kita dapat mempelajari hubungan persekutuan yang terjadi antara liana/tali kupukupu (B. acuminata) dengan pohon inangnya secara alami di hutan dataran rendah TWA Gunung Meja, sehingga dapat dilakukan tindakan konservasi baik konservasi ex-situ maupun konservasi in-situ. Dalam penerapannya misalnya untuk pembudidayaan dapat dilaksanakan dengan menanam inang yang mempunyai hubungan erat atau yang lebih banyak berasosiasi dengan tali kupu-kupu sehingga dapat mempertahankan keberlanjutan dari tali kupu-kupu (B. acuminata) tersebut.

Tujuan penelitian ini adalah untuk mengetahui asosiasi tali kupu-kupu (B. acuminata) dengan pohon inangnya serta untuk mengetahui habitat dari tali kupu-kupu ini pada hutan dataran rendah TWA Gunung Meja. data hasil penelitian ini diharapkan dapat menjadi hasil penelitian ini diharapkan dapat menjadi dasar dalam rangka pembudidayaan dan tindakan konservasi baik konservasi eksitu maupun insitu dari jenis liana ini.

\section{METODE PENELITIAN}

\section{Tempat dan Obyek Penelitian}

Penelitian dilakukan pada Plot Monitoring Biodiversitas Flora yang terdapat pada kawasan hutan dataran rendah TWA Gunung Meja Manokwari selama 2 minggu yaitu dari tanggal 3 s/d 17 Maret tahun 2014. Yang menjadi obyek penelitian adalah liana atau tali kupukupu (B. acuminata) yang tumbuh pada pohon inang yang terdapat pada Plot Monitoring Biodiversitas Flora hutan dataran rendah TWA Gunung Meja. Detail lokasi plot pengamatan dapat dilihat pada gambar 1.

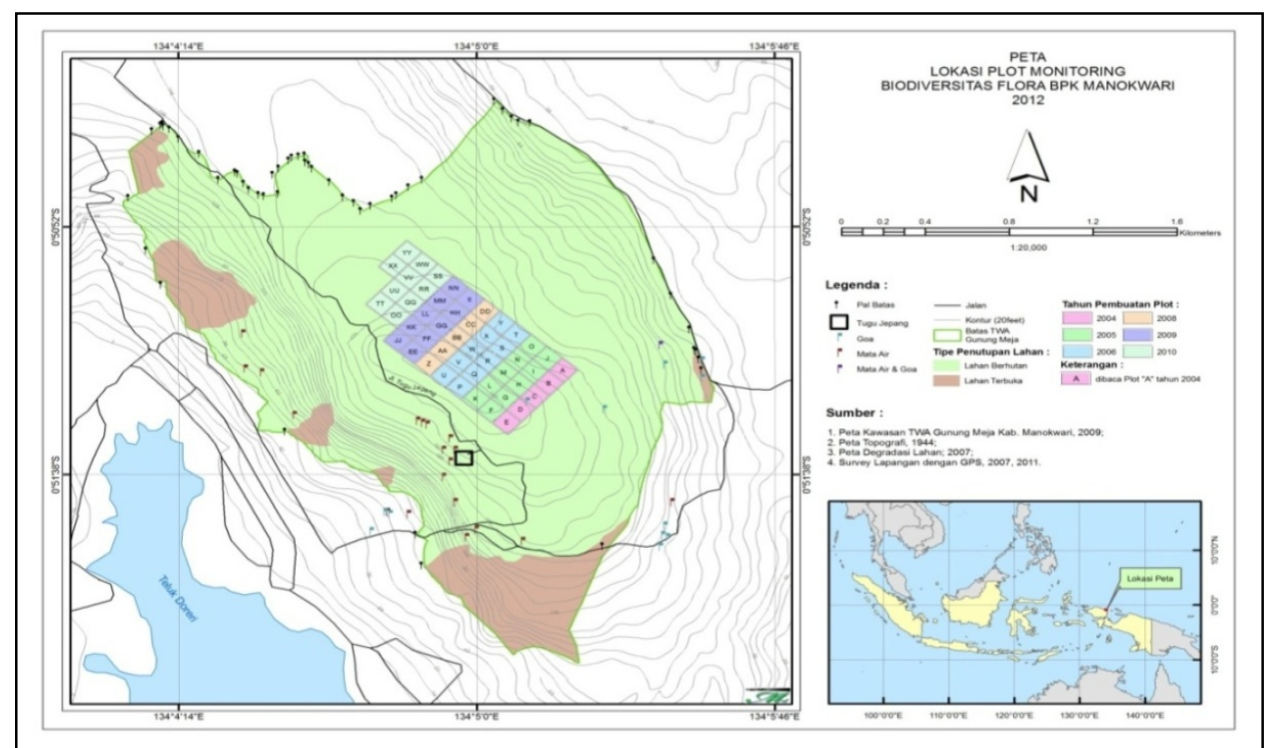

Gambar 1. Peta lokasi penelitian pada plot monitoring pada hutan TWA Gunung Meja

\section{Metode dan Teknik Penelitian}

Metode yang digunakan dalam peneltian ini adalah metode deskriptif dengan teknik survei. Penentuan dan pembuatan jalur pengamatan dengan luas areal yang menjadi obyek penelitian adalah 50 Ha. Dengan panjang 1000 meter dan lebar $500 \mathrm{~m}$. Base line (jalur induk) dibuat searah atau sejajar jalan raya dengan panjang 1000 meter. Panjang masing-masing anak jalur 500 meter. Dan lebar anak jalur 20 
meter. Maka banyaknya jalur pengamatan = panjang jalur induk dibagi lebar anak jalur $=$ 1000 meter : 20 meter $=50$ jalur.
Dengan intensitas sampling yang digunakan $20 \%=20 / 100 \times 50=10$ jalur.

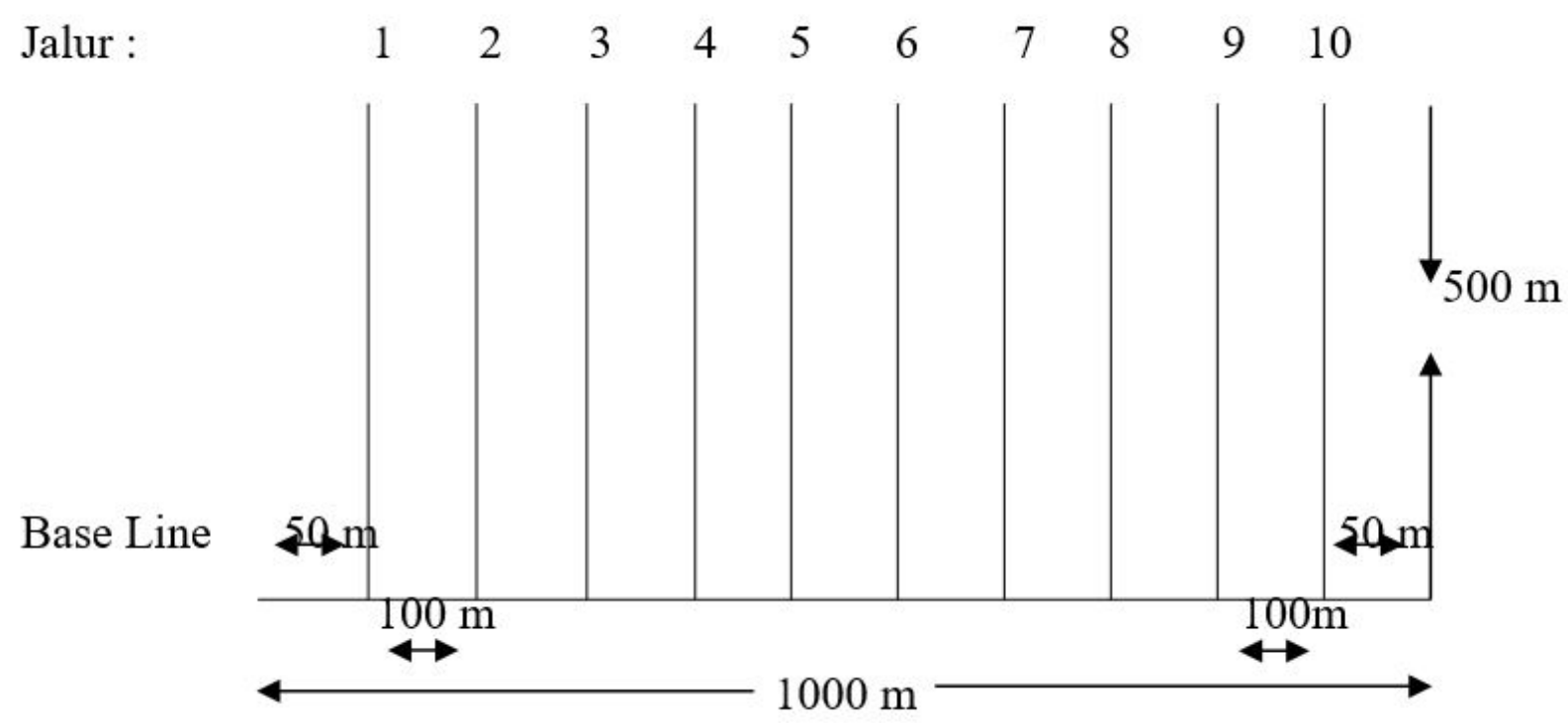

Gambar 2. Bentuk jalur pengamatan

\section{Variabel dan Data Pengamatan}

Variabel yang diamati adalah asosiasi antara liana atau tali kupu-kupu dengan pohon inang yang meliputi kehadiran jenis tali kupu-kupu dan pohon inang serta pohon lain yang tidak berasosiasi dengan liana tersebut yang dijumpai dalam jalur pengamatan. Data pengamatan yang diamati dalam penelitian ini terdiri dari :

1. Liana atau tali kupu-kupu.

- Jumlah B. acuminata yang berasosiasi dengan pohon inang

2. Pohon Inang

- Jenis dan jumlah pohon inang yang ditumbuhi $B$. acuminata.

- Jenis dan jumlah pohon inang yang tidak ditumbuhi B. acuminata.

- Diameter (cm) dan tinggi pohon (m).

- Pohon inang lain yang ditumbuhi $B$. acuminata.

\section{Pengolahan Data}

Pengolahan data akan dilakukan dengan pendekatan Indeks Asosiasi (IA) berdasarkan kehadiran ( $\mathrm{P}=$ presence $)$ dengan menggunakan rumus menurut Mueller-Dombois dan Ellenberg (1974), dalam Baratawinata (2001) yang dimodifikasi sesuai dengan tujuan penelitian.

$$
\mathrm{IAP}=\frac{\mathrm{C}}{\mathrm{A}+\mathrm{B}+\mathrm{C}} \times 100(\%)
$$

Keterangan :

IAP $=$ Indeks asosiasi berdasarkan kehadiran jenis

A = Banyaknya pohon yang tidak ditumbuhi tali kupu-kupu

$\mathrm{B}=$ Banyaknya pohon inang lain yang ditumbuhi tali kupu-kupu

$\mathrm{C}=$ Jumlah pohon inang yang ditumbuhi oleh tali kupu-kupu 
Penentuan tingkat asosiasi yang digunakan adalah dihitung setelah nilai dari perhitungan indeks asosiasi berdasarkan kehadiran jenis sebagai berikut:

Nilai Maximum IAP - Nilai Minimum IAP

$$
\text { Banyaknya Kelas }
$$

Dengan pembagian kelas sebagai berikut (Bratawinata 2001) :

\begin{tabular}{ccc}
\hline No. & Kelas & Kriteria \\
\hline 1. & I & Tidak erat \\
2. & II & Kurang erat \\
3. & III & Erat \\
4. & IV & Sangat erat \\
\hline
\end{tabular}

\section{Analisis Data}

Data yang dikumpulkan akan dianalisis secara deksriptif dan disajikan dalam bentuk tabel dan gambar.

\section{HASIL DAN PEMBAHASAN}

\section{Jenis Pohon Pada Lokasi Penelitian}

Hasil penelitian yang dilakukan pada plot monitoring biodiversitas flora TWA Gunung Meja seluas 10 ha dari total 50 ha, memiliki
105 jenis pohon yang tergolong dalam 31 famili dengan jumlah total individu sebanyak 439 pohon. Famili yang dominan adalah Meliaceae dengan 5 marga dan 11 jenis, marga dominan adalah Artocarpus, Ficus, Litsea, Sterculia dan Syzygium dengan 4 jenis, sedangkan untuk jenis yang paling dominan adalah Pometia coreacea Radlk dengan jumlah 31 individu. Indeks keanekaragaman jenis atau indeks ShannonWienners (Ludwig and Reynolds 1988) untuk tingkat pohon pada kawasan ini adalah 4,035 atau tergolong sangat tinggi. Hal ini menunjukan bahwa Plot Monitoring Biodiversitas Flora seluas 15 ha pada kawasan hutan dataran rendah TWA Gunung Meja memiliki keanekaragaman hayati yang cukup tinggi.

Dari data tersebut dapat disimpulkan bahwa tidak seharusnya famili yang dominan mempunyai marga yang dominan. Demikian pula marga yang dominan tidak harus diikuti oleh spesies yang dominan. Komposisi jenis 10 pohon dominan pada Plot Monitoring Biodiversitas Flora seluas 15 ha di TWA Gunung Meja Kabupaten Manokwari secara lengkap dapat dilihat pada tabel 1.

Tabel 1. Komposisi jenis 10 pohon dominan pada plot monitoring 15 ha TWA Gunung Meja

\begin{tabular}{clccccccc}
\hline No. & \multicolumn{1}{c}{ Nama jenis } & $\mathrm{K}$ & $\begin{array}{c}\mathrm{KR} \\
(\%)\end{array}$ & $\mathrm{F}$ & $\begin{array}{c}\text { FR } \\
(\%)\end{array}$ & D & $\begin{array}{c}\text { DR } \\
(\%)\end{array}$ & $\begin{array}{c}\text { INP } \\
(\%)\end{array}$ \\
\hline 1 & Pometia coreacea & 11.923 & 7.094 & 0.400 & 6.683 & 4.018 & 16.127 & 29.905 \\
2 & Pometia pinnata & 14.615 & 8.696 & 0.415 & 6.940 & 1.199 & 4.814 & 20.450 \\
3 & Alstonia scholaris & 10.385 & 6.178 & 0.323 & 5.398 & 1.925 & 7.726 & 19.302 \\
4 & Artocarpus incisus & 6.154 & 3.661 & 0.154 & 2.571 & 1.318 & 5.289 & 11.521 \\
5 & Pimelodendron amboinicum & 6.923 & 4.119 & 0.262 & 4.370 & 0.486 & 1.952 & 10.441 \\
6 & Pterocymbium beccari & 2.308 & 1.373 & 0.077 & 1.285 & 1.339 & 5.376 & 8.034 \\
7 & Antiaris toxicaria & 5.000 & 2.975 & 0.185 & 3.085 & 0.448 & 1.797 & 7.856 \\
8 & Streblus elongata & 5.000 & 2.975 & 0.169 & 2.828 & 0.459 & 1.841 & 7.644 \\
9 & Medusanthera laxiflora & 5.385 & 3.204 & 0.185 & 3.085 & 0.217 & 0.872 & 7.161 \\
10 & Pterygota hordfieldii & 3.462 & 2.059 & 0.123 & 2.056 & 0.757 & 3.039 & 7.155 \\
\hline
\end{tabular}


Dari tabel 1, terlihat bahwa pohon yang paling dominan dan menjadi penciri utama di lokasi penelitian adalah $P$. coreacea jenis ini dominan karena memiliki rata-rata pertumbuhan diameter yang baik. Jenis dominan lainnya berturut-turut adalah $P$. pinnata dan A. scholaris. Jenis $P$. pinnata menjadi pohon dominan kedua disebabkan karena jumlah individu yang banyak dan penyebarannya sangat merata di lokasi penelitian dengan rata-rata pertumbuhan diameter yang cukup baik namun masih rendah jika dibandingkan dengan $P$. coreaceae. Sedangkan jenis A. scholaris menjadi pohon dominan ketiga karena memiliki rata-rata pertumbuhan diameter yang lebih baik jika dibandingkan dengan $P$. pinnata namun jumlah individu serta penyebarannya masih rendah dibandingkan $P$. pinnata.

Menurut Lekitoo (2011), secara umum penyebaran jenis $P$. coreacea dan $P$. pinnata cukup merata di lokasi penelitian plot monitoring flora TWA Gunung Meja disebabkan karena kedua jenis ini memiliki buah yang dikonsumsi oleh semua satwa liar seperti burung, kelelawar, kus-kus dan lainnya, sehingga pemencaran biji kedua jenis tersebut merata pada lokasi penelitian.

\section{Jenis Pohon Inang Yang Ditumbuhi}

Pengamatan asosiasi tali kupu-kupu dan pohon inang hanya dilakukan pada sepuluh jenis pohon yang paling dominan pada lokasi penelitian. Dari hasil penelitian diketahui bahwa jenis pohon inang yang ditumbuhi tali kupu-kupu sebanyak 10 pohon atau 9,52\%. Famili yang dominan adalah Sapindaceae dengan total individu 17, marga dominan adalah Pometia, sedangkan jenis yang dominan atau paling banyak berasosiasi dengan tali kupu-kupu adalah $P$. pinnata dengan 11 individu. Hal ini sesuai dengan pendapat Richard (1975) dan Ewusie (1990) yang menyatakan bahwa umumnya di daerah tropis pohon-pohon dalam hutan ditumbuhi liana yang hidupnya menempel pada pohon inang yang menjulur hingga ke tajuk pohon. Jenis-jenis pohon inang yang ditumbuhi oleh tali kupukupu (B. acuminata) secara lengkap dapat dilihat pada tabel 2 .
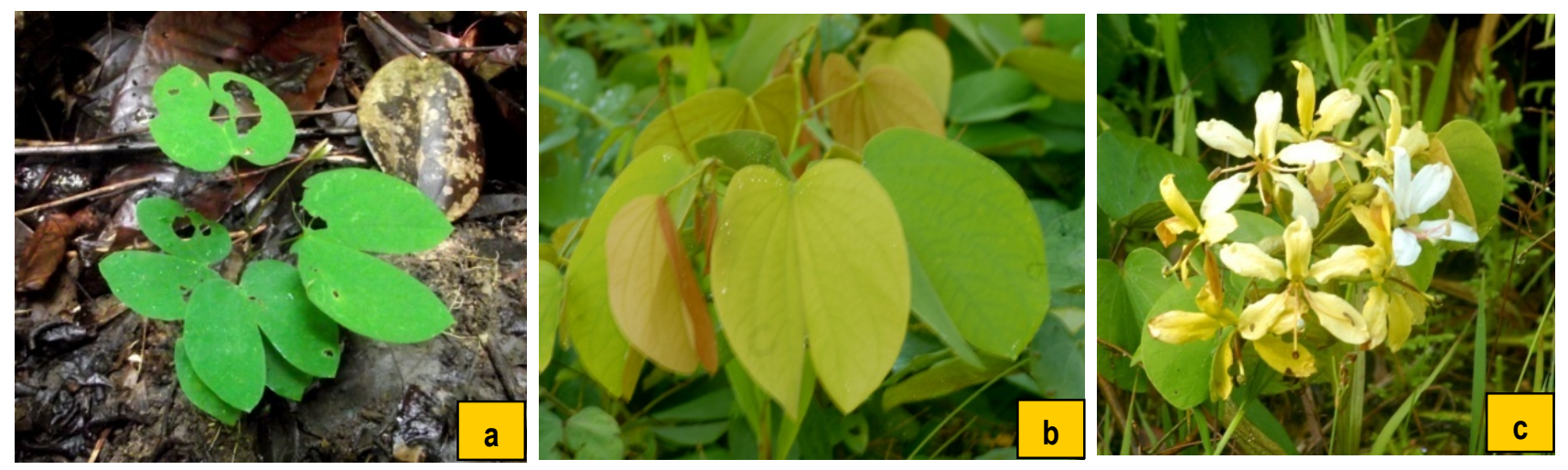

Gambar 3. Karakteristik morfologi jenis B. acuminata; a. anakan; b. daun; c. bunga 
Tabel 2. Jumlah pohon inang yang ditumbuhi tali kupu-kupu (B. acuminate)

\begin{tabular}{|c|c|c|c|c|c|}
\hline \multirow{2}{*}{ No. } & \multirow{2}{*}{ Jenis pohon inang } & \multirow{2}{*}{$\begin{array}{l}\Sigma \text { pohon inang } \\
\text { terdapat tali kupu- } \\
\text { kupu }\end{array}$} & \multicolumn{3}{|c|}{ Kisaran diameter } \\
\hline & & & $30-39$ & $40-49$ & $>50$ \\
\hline 1. & Pometia coreacea & 3 & 1 & 1 & 1 \\
\hline 2. & Pometia pinnata & 11 & 3 & 6 & 2 \\
\hline 3. & Alstonia scholaris & 4 & 1 & 2 & 1 \\
\hline 4. & Artocarpus incisus & 3 & 1 & 2 & - \\
\hline 5. & Pimelodendron amboinicum & 4 & 2 & 2 & - \\
\hline 6. & Pterocymbium beccari & 1 & - & 1 & - \\
\hline 7. & Antiaris toxicaria & 1 & 1 & - & - \\
\hline 8. & Streblus elongata & 2 & 1 & 1 & - \\
\hline 9. & Medusanthera laxiflora & 2 & 2 & - & - \\
\hline \multirow[t]{2}{*}{10.} & Pterygota hordfieldii & 3 & 1 & 2 & - \\
\hline & Jumlah & 34 & 13 & 17 & 4 \\
\hline
\end{tabular}

Sumber : Data primer tahun 2014

Dari tabel 2 terlihat bahwa tali kupu-kupu ternyata berasosiasi dengan 10 jenis pohon dominan di lokasi penelitian. Jenis yang paling banyak ditumbuhi tali kupu-kupu adalah $P$. pinnata (11 pohon atau sebanyak 32,35\%) diikuti $A$. scholaris dan $P$. amboinicum (4 pohon atau $11,76 \%)$. Kenyataan di lapangan menunjukan rata-rata pohon inang yang terdapat tali kupu-kupu (B. acuminate), umumnya merupakan pohon berukuran kecil sampai besar yaitu berdiameter $30-75 \mathrm{~cm}$ dengan tinggi 15-36 m, sehingga cukup mendapat cahaya matahari. Adanya kecenderungan (trend) pohon matoa sebagai inang tali kupu-kupu karena adanya sifat alami karakter tali tersebut, dimana jenis ini umumnya merupakan liana berkayu yang berukuran besar (diameter 20-25 cm) sehingga memiliki berat yang dapat mencapai 1 ton. Kecenderungan tersebut mengakibatkan dalam distribusi dan pemencaran bijinya, liana ini secara alami akan beradaptasi dengan pohon inangnya sesuai dengan karakternya yaitu pohon inang tersebut harus kuat sehingga mampu menahan keberadaan jenis liana tersebut di alam dalam jangka waktu tertentu. Hal ini dapat dilihat pada tabel 2 yang menunjukkan bahwa tali kupu-kupu paling banyak tumbuh pada pohon yang memiliki diameter diatas $40 \mathrm{~cm}$. Jhons (1997) dan Lekitoo et al. (2008), yang menyatakan bahwa pohon-pohon inang tali kupu-kupu seperti yang ditampakkan pada tabel 2 umumnya merupakan pohon berukuran besar atau raksasa yang umumnya tumbuh tersebar pada hutan dataran rendah di Papua.

Jumlah Pohon Inang Yang Tidak Ditumbuhi

Jumlah pohon inang (pohon dominan) yang tidak ditumbuhi tali kupu-kupu sebanyak 152 pohon yang terdiri dari 10 jenis. Jumlah pohon inang yang tidak ditumbuhi tali kupu-kupu disajikan pada tabel 3 . 
Tabel 3. Jumlah pohon inang yang tidak ditumbuhi $B$. acuminate

\begin{tabular}{|c|c|c|}
\hline No. & Jenis pohon inang & $\begin{array}{l}\text { Jumlah pohon inang } \\
\text { tidak terdapat tali kupu-kupu }\end{array}$ \\
\hline 1. & Pometia coreacea & 28 \\
\hline 2. & Pometia pinnata & 27 \\
\hline 3. & Alstonia scholaris & 23 \\
\hline 4. & Artocarpus incisus & 14 \\
\hline 5. & Pimelodendron amboinicum & 14 \\
\hline 6. & Pterocymbium beccari & 5 \\
\hline 7. & Antiaris toxicaria & 12 \\
\hline 8. & Streblus elongata & 11 \\
\hline 9. & Medusanthera laxiflora & 12 \\
\hline \multirow[t]{2}{*}{10.} & Pterygota hordfieldii & 6 \\
\hline & Jumlah & 152 \\
\hline
\end{tabular}

Sumber : Data primer tahun 2014

Tabel 3 menunjukkan bahwa jumlah pohon inang yang tidak ditumbuhi tali kupu-kupu terbanyak adalah $P$. coreacea (28 pohon). Hal ini disebabkan karena adanya distribusi dan penyebaran tali kupu-kupu yang tidak merata sehingga kesempatan penyebaran jenis ini secara alami pun memiliki kecenderungan tidak merata pada lokasi penelitian. Tali kupu-kupu sebagai tumbuhan umumnya memiliki strategi dalam proses regenerasi dan penyebaran jenisnya, namun faktor alam (kondisi ekologi) tetap merupakan faktor utama penentu bagi proses regenarasi tumbuhan secara alami. Proses seleksi alam dalam hal regenerasi dan distribusi tumbuhan tali kupu-kupu tersebut dikenal dengan seleksi r, dimana pada saat awal populasi besar namun pada saat akhir populasi tersebut akan cenderung mengecil atau cenderung berbentuk pyramid (Ewusie 1990).

\section{Asosiasi Tali Kupu-kupu Dengan Pohon Inang}

Asosiasi antara tali kupu-kupu dengan pohon inang ditentukan dengan persen indeks asosiasi (IAP) berdasarkan kehadiran atau ketidakhadiran spesies. Hasil perhitungan IAP dari tali kupu-kupu dengan pohon inang serta kriteria tingkat asosiasi (keeratan hubungan) disajikan pada tabel 4. Tali kupu-kupu merupakan liana berkayu yang memanjat dan tumbuh pada pohon untuk mendapat sinar matahari. Sebagai tumbuhan liana, tumbuhan ini tidak tergantung pada bahan makanan yang berasal dari pohon inangnya, karena mendapatkan unsur hara dari mineral-mineral yang langsung dari tanah (berbeda dengan jenis tumbuhan epifit yang mendapatkan makanan lewat udara, air hujan atau aliran batang dan cabang pohon inang, serta bagian kulit pohon yang terkelupas). Disamping itu sebagai tumbuhan liana, $B$. acuminata mampu melakukan fotosintesis untuk mendapatkan makanan bagi pertumbuhannya, sehingga liana ini bukan bersifat parasit yang umumnya merugikan karena mengambil makanan dari pohon inangnya (Indriyanto 2005). Berdasarkan tabel 4 diketahui bahwa pohon A. toxicaria, $M$. laxiflora, S. elonga dan $P$. beccarii memiliki keeratan asosiasi yang sangat rendah atau tidak erat dengan tali kupu-kupu. Sedangkan jenis 
pohon P. coreacea, A. scholaris, A. incissus, $P$. amboinicum dan $P$. horsfieldii memiliki keeratan asosiasi yang rendah atau kurang erat. Namun sebaliknya jenis pohon inang $P$. pinnata. mempunyai tingkat asosiasi tinggi dengan tali kupu-kupu (B. acuminata) dengan hubungan keeratan yang sangat erat. Hal ini disebabkan karena $P$. pinnata memiliki karakter morfologi yaitu kulit batang yang kasar dan agak berlekuk serta kuat hingga mampu menahan tali kupu-kupu hingga dewasa, memiliki tutupan tajuk rindang tetapi percabangan yang banyak sehingga memungkinkan peneriman cahaya matahari yang cukup bagi pertumbuhan liana tersebut, namun jika dilihat dari tabel di atas tingkat keeratan pohon $P$. pinnata hanya mencapai $2,506 \%$ walaupun demikian $P$. pinnata yang paling tertinggi.

Tabel 4. Asosiasi pohon inang dengan tali kupu-kupu (B. acuminata)

\begin{tabular}{clcc}
\hline No. & Jenis pohon inang & $\begin{array}{c}\text { IAp } \\
(\%)\end{array}$ & Tingkat asosiasi \\
\hline 1. & Pometia coreacea & 0.683 & Tidak erat \\
2. & Pometia pinnata & 2.506 & Sangat erat \\
3. & Alstonia scholaris & 0.911 & Kurang erat \\
4. & Artocarpus incisus & 0.683 & Tidak erat \\
5. & Pimelodendron amboinicum & 0.911 & Kurang erat \\
6. & Pterocymbium beccari & 0.228 & Tidak erat \\
7. & Antiaris toxicaria & 0.228 & Tidak erat \\
8. & Streblus elongata & 0.456 & Tidak erat \\
9. & Medusanthera laxiflora & 0.456 & Tidak erat \\
10. & Pterygota horsefieldii & 0.683 & Tidak erat \\
\hline
\end{tabular}

Sumber : Data primer tahun 2014

Tabel 5. Tingkat asosiasi keeratan hubungan antara tali kupu-kupu (B. acuminata) dan pohon inang

\begin{tabular}{ccc}
\hline Kelas & Interval & Kriteria \\
\hline I & $0,2280-0,7975$ & Tidak erat \\
II & $0,7975-1.3670$ & Kurang erat \\
III & $1,3670-1,9365$ & Erat \\
IV & $1,9365-2,5060$ & Sangat erat \\
\hline
\end{tabular}

Sumber : Data primer tahun 2014

Dari tabel 4 tersebut dapat dibuat kriteria tingkat asosiasi (hubungan keeratan) antar spesies, dengan perhitungan sebagai berikut: $(2,506-0,228): 4=2,278: 4=0,569$. Hasil penelitian juga menunjukan bahwa pohon inang yang terdapat tali kupu-kupu bervariasi dalam diameter dan tingginya dan umumnya menempati strata pertama (dominan) dan kedua (co-dominan) dari lapisan tajuk teratas. Khusus untuk pohon inang matoa ( $P$. pinnata) yang paling banyak ditemukan jenis liana ini, tinggi rata-rata 27 meter dengan diameter rata-rata 
mencapai 48,5 cm, sehingga memungkinkan untuk penerimaan cahaya matahari bagi liana tersebut. Hal ini mengindikasikan bahwa jenis pohon inang $P$. pinnata merupakan jenis yang lebih cocok bagi pertumbuhan tali kupukupu.

\section{KESIMPULAN}

Jenis pohon yang ditemukan pada plot monitoring flora hutan dataran rendah TWA Gunung Meja seluas 15 ha sebanyak 105 jenis, yang terdiri dari 71 marga dan 31 famili dengan jenis yang paling dominan adalah $P$. coreacea. Terdapat 10 jenis pohon yang berasosiasi dengan tali kupu-kupu yaitu $P$. coreacea, $P$. pinnata, $A$. scholaris, $A$. incissus, $P$. amboinicum, $P$. beccarii, $A$. toxicaria, $S$. elongate, M. laxiflora dan Pterygota horfieldii, dengan jumlah individu terbanyak adalah $P$. pinnata sebanyak 11 pohon. Secara umum tngkat asosiasi tali kupu-kupu dengan pohon inang $P$. pinnata adalah sangat erat $(2,506 \%)$, tingkat asosiasi $B$. acuminata kurang erat dengan pohon inang $A$. scholaris $(0,911 \%)$ dan $P$. amboinicum $(0,911 \%)$, tingkat asosiasi $B$. acuminata tidak erat dengan pohon inang $P$. coreacea $(0,683 \%), P$. horsfieldii $(0,683 \%)$, A. incisus $(0,683 \%), P$. beccarii $(0,228 \%), A$. toxicaria $(0,228 \%)$, S. elongata $(0,456 \%)$ dan M. laxiflora $(0,456 \%)$.

\section{DAFTAR PUSTAKA}

Bratawinata AA. 2001. Ekologi hutan hujan tropis dan metoda analisis hutan. Departemen Pendidikan Nasional Direktorat Jendral Pendidikan Tinggi Badan Kerja Sama Perguruan Tinggi Negeri Indonesia Timur (BKS- PTN dan - INTIM).
Ewusie JY. 1990. Pengantar ekologi tropika. ITB. Bandung.

Indriyanto. 2005. Ekologi hutan. Direktorat Jenderal Pendidikan Tinggi. Jakarta: Departemen Pendidikan Nasional.

Lekitoo K, Remetwa H, Matani OPM, Heatubun CD. 2008. Keanekaragaman flora Taman Wisata Alam Gunung Meja Papua Barat (Jenis-Jenis Pohon-Bagian 1). Balai Penelitian Kehutanan Manokwari. Manokwari.

Lekitoo K. 2011. Keanekaragaman jenis dan pola komunitas pada plot monitoring biodiversitas flora Taman Wisata Alam Gunung Meja Kabupaten Manokwari. [Tesis]. Program Pascasarjana Kehutanan, Universitas Gadjah Mada, Yogyakarta.

Lekitoo K, Peday HFZ, Panambe N, Cabuy RL. 2017. Ecological and ethnobotanical facet of 'Kelapa Hutan' (Pandanus spp.) and perspectives towards its existence and benefit. International Journal of Botany 13: 103-114.

Ludwig JA, Reynolds JF. 1988. Statistical ecology. John Wiley and Sons, New York.

Richard PW. 1975. The tropical rain forest. An ecological study. Canbridge Univ. Press. Canbridge.

Wattimury JK. 2007. Kajian jenis-jenis inang sebagai indikator kehadiran anggrek tebu (Grammatophyllum speciosum Blume) pada kawasan hutan dataran rendah Warbefor distrik Manokwari Utara kabupaten Manokwari. [Skripsi]. Fakultas Kehutanan Universitas Negeri Papua, Manokwari. 